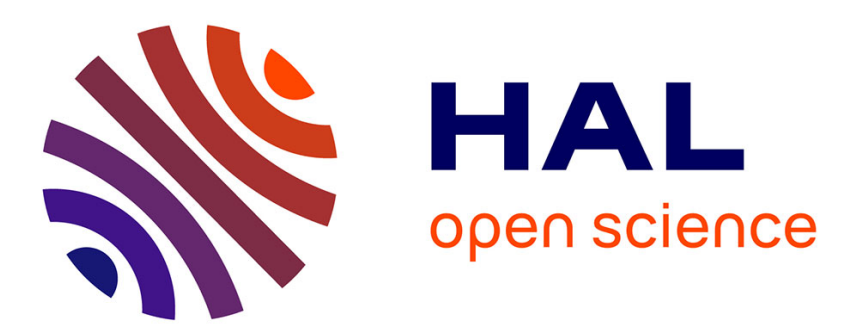

\title{
Operando Neutron Powder Diffraction Using Cylindrical Cell Design: The Case of LiNi0.5Mn1.5O4 vs Graphite
} Lucien Boulet-Roblin, Philippe Borel, Denis Sheptyakov, Cécile Tessier, Petr Novak, Claire Villevieille

\section{- To cite this version:}

Lucien Boulet-Roblin, Philippe Borel, Denis Sheptyakov, Cécile Tessier, Petr Novak, et al.. Operando Neutron Powder Diffraction Using Cylindrical Cell Design: The Case of LiNi0.5Mn1.5O4 vs Graphite. Journal of Physical Chemistry C, 2016, 120 (31), pp.17268-17273. 10.1021/acs.jpcc.6b05777 . hal02632061

\section{HAL Id: hal-02632061 \\ https://hal.science/hal-02632061}

Submitted on 27 May 2020

HAL is a multi-disciplinary open access archive for the deposit and dissemination of scientific research documents, whether they are published or not. The documents may come from teaching and research institutions in France or abroad, or from public or private research centers.
L'archive ouverte pluridisciplinaire HAL, est destinée au dépôt et à la diffusion de documents scientifiques de niveau recherche, publiés ou non, émanant des établissements d'enseignement et de recherche français ou étrangers, des laboratoires publics ou privés. 


\title{
Operando Neutron Powder Diffraction using
}

\section{Cylindrical Cell Design: The Case of $\mathrm{LiNi}_{0.5} \mathrm{Mn}_{1.5} \mathrm{O}_{4}$}

\author{
vs. Graphite
}

Lucien Boulet-Roblin,,${ }^{\dagger}$ Philippe Borel,,${ }^{\#}$ Denis Sheptyakov,,${ }^{\sharp}$ Cécile Tessier,,$\#$ Petr Novák,, and

Claire Villevieille ${ }^{\dagger, I^{*}}$

† Paul Scherrer Institute, Electrochemistry Laboratory, CH-5232 Villigen PSI, Switzerland

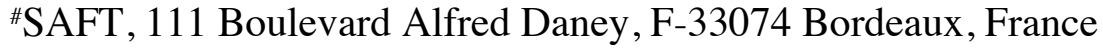

* Paul Scherrer Institute, Laboratory for Neutron Scattering and Imaging, CH-5232 Villigen PSI, Switzerland

${ }^{1}$ Address: Paul Scherrer Institute, CH-5232 Villigen PSI, Switzerland 


\begin{abstract}
In order to follow the structural changes correlated to the evolution of the lithium content in high voltage battery systems (based on a disordered $\mathrm{LiNi}_{0.5} \mathrm{Mn}_{1.5} \mathrm{O}_{4}(\mathrm{~d}-\mathrm{LNMO}$ ) and a graphite electrode), we developed a new cylindrical cell suitable for operando neutron diffraction measurements. The cell, containing two grams of electroactive materials, is able to cycle at a fast rate (1C) with reliable electrochemical performance. The operando neutron diffraction measurements revealed the evolution of the lattice parameters of both the d-LNMO and graphite phases, notably showing the transitions between graphite lithiation stages. Furthermore, as a result of Rietveld refinements, the lithium consumption could be attributed mainly to the formation of a solid electrolyte interphase (SEI) layer on the graphite surface. This approach provides important insights helping to optimize the loading of the electroactive materials in batteries, especially for high voltage systems in which side reactions and lithium consumption can occur during cycling.
\end{abstract}




\section{INTRODUCTION}

A mechanistic understanding the reactions that take place in the most promising electrode materials used in Li-ion batteries is crucial for their further development, especially if electric mobility applications are targeted. Indeed, improvements in terms of energy density are needed for competitive performance with gasoline engines. $\mathrm{LiNi}_{0.5} \mathrm{Mn}_{1.5} \mathrm{O}_{4}$ spinel (LNMO) is the cathode material of choice for future $5 \mathrm{~V} \mathrm{Li}$-ion batteries because of its high energy density $(\sim 610 \mathrm{Wh} / \mathrm{kg})^{1}$ and an average cycling voltage of $\sim 4.7 \mathrm{~V}$ vs. $\mathrm{Li}^{+} / \mathrm{Li}$, involving mainly the redox couples $\mathrm{Ni}^{3+} / \mathrm{Ni}^{2+}$ and $\mathrm{Ni}^{4+} / \mathrm{Ni}^{3+} .{ }^{2} \mathrm{LNMO}$ exists as two polymorphs, "disordered" (d-LNMO, $F d-3 m$ ) or "ordered" (o-LNMO, $\mathrm{P}_{3} 32$ ) spinel, ${ }^{3}$ and thus far, the disordered form has outperformed the ordered from an electrochemical point of view. ${ }^{1,4,5} \mathrm{~d}-\mathrm{LNMO}$ is characterized by its statistical distribution of $\mathrm{Ni}$ and Mn atoms on the shared 16d sites, whereas o-LNMO has two distinct atomic sites for the transition metals. In general, the d- and o-LNMO polymorphs exhibit stable electrochemical performance when cycled against metallic lithium, with practical specific charges of ca. $140 \mathrm{mAh} / \mathrm{g}$. Unfortunately, in the full-cell configuration using graphite as the counter electrode, rapid degradation of the cycling performance has been reported with different fading mechanisms.${ }^{6,7}$ In general, three main phenomena can explain this trend: i) electrolyte decomposition at high voltage (above $4.3 \mathrm{~V}$ vs. $\mathrm{Li}^{+} / \mathrm{Li}$ in a typical carbonate electrolyte), ${ }^{8,9}$ ii) transition metal dissolution (i.e., where $\mathrm{Ni}$ and $\mathrm{Mn}$ atoms migrate and interact with the graphite counter electrode),${ }^{10}$ and iii) lithium consumption (e.g., through formation of a solid electrolyte interphase (SEI) layer or LiF).,11

Most of the abovementioned phenomena lead to structural changes; thus, neutron powder diffraction (NPD) is a superlative technique by which to follow both these changes and the fate of lithium during (de)lithiation due to its relatively good neutron scattering properties. ${ }^{12}$ Unfortunately, because the interaction between neutrons and matter is weak, large amounts of 
electroactive materials must be cycled to obtain a good signal, which can quite often be detrimental to good electrochemical performance. Thus, one of the challenges of the operando NPD measurement is to develop a cell capable of cycling a large quantity of active material while obtaining i) good electrochemical performance (especially for long-term cycling) and ii) sufficient pattern quality to allow Rietveld refinement analysis.

A number of groups have reported different cell designs for operando NPD measurements but, to the best of our knowledge, none to date have succeeded in obtaining a relatively fast cycling rate (with good electrochemical performance) and lithium determination with Rietveld refinement. ${ }^{13}$ Commercial cylindrical cells are known to cycle large amounts of active materials with excellent performances but, regrettably, their neutron diffraction patterns have poor signalto-noise ratios because of the large amount of hydrogen in the electrolyte/separator and numerous cell parts/elements. ${ }^{14}$

Therefore, in order to study the changes that occur in d-LNMO versus graphite during cycling, a cylindrical cell based on the 18650 design was developed to perform operando NPD experiments under the following constraints: i) high amount of active materials (gram-scale), ii) choice of deuterated electrolyte, and iii) thin polymeric separator. First, the electrochemical performance of this new cylindrical cell will be presented and discussed. Then, the results of the operando NPD measurements will be reported, and a structural analysis of the changes occurring in the d-LNMO and graphite matrices, confirmed by ex situ measurements of both materials, will be discussed. 


\section{EXPERIMENTAL SECTION}

The cylindrical cell used for this study is depicted in Figure 1. Compared to a commercial 18650 cylindrical cell, three main changes were introduced: i) the electrical connections (+ and - ) were both placed on the top of the cell (Figure 1a); ii) the base of the cell was modified by the addition of a screw, to facilitate filling with the deuterated electrolyte (Figure 1b); and iii) the inner core used to roll up the electrodes and the separator was removed prior to assembling the cell (to improve the signal-to-noise ratio).

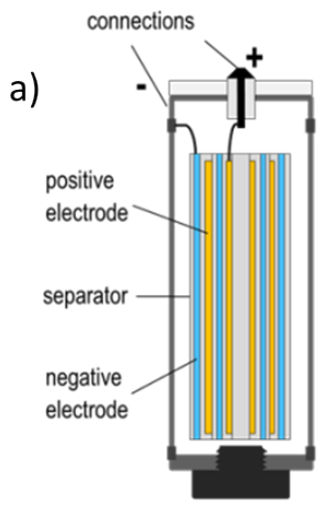

b)

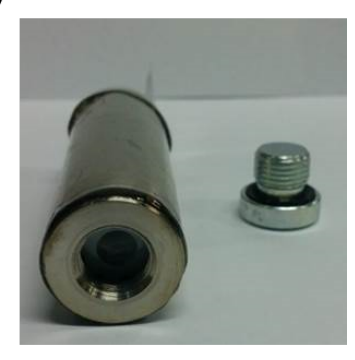

Figure 1. a) Scheme of the cylindrical cell used for operando neutron powder diffraction.

b) Bottom-view image of the cylindrical cell showing where the screw is placed.

The positive electrode was prepared by casting a mixture of $92 \mathrm{wt} \% \mathrm{~d}$-LNMO (roughly $2 \mathrm{~g}$, crystallographic data in Figure S1 and Table S1), 4 wt\% conducting carbon, and 4 wt\% PVDF binder suspended in $N$-methyl-2-pyrrolidinone onto an aluminum foil for use as the current collector. The cast slurry was dried at $80^{\circ} \mathrm{C}$ under vacuum overnight. The negative electrode (provided by SAFT), based on a mixture of graphite (96 wt $\%$ ) and a sodium carboxymethylcellulose binder (Na-CMC, $4 \mathrm{wt} \%$ ), was cast onto a copper foil for use as the current collector. Each electrode was coated on both sides. A polyethylene/polypropylene (PE/PP) 
polyolefin ( $20 \mu \mathrm{m}$ thick) separator was placed between the positive and negative electrodes, prior to rolling. After assembly, the cylindrical cells were dried at $50^{\circ} \mathrm{C}$ overnight and then stored in an argon-filled glove box. The cells were filled with deuterated LP30 electrolyte for operando measurements ( $\sim 2 \mathrm{~mL}, \quad 1 \mathrm{M} \mathrm{LiPF}_{6}$ (Sigma Aldrich) in $1: 1 \mathrm{w} / \mathrm{w}$ deuterated ethylene carbonate/deuterated dimethyl carbonate (Armar Chemicals)) and a non-deuterated standard LP30 electrolyte (BASF) for other experiments, respectively. The cycling of the cylindrical or standard (described elsewhere) $)^{15}$ cells was carried out galvanostatically between 3.5 and $4.8 \mathrm{~V}$ with a VMP300 potentiostat (Bio-Logic) at room temperature $\left(25^{\circ} \mathrm{C}\right)$. The $\mathrm{C}$-rates (the $1 \mathrm{C}$ rate is equivalent to $1 \mathrm{~h}$ per charge/discharge) were calculated assuming experimental specific charges of $135 \mathrm{mAh} / \mathrm{g}$ for d-LNMO and $340 \mathrm{mAh} / \mathrm{g}$ for graphite. Prior to operando measurement, the cylindrical cell was pre-cycled in the laboratory at the $\mathrm{C} / 10$ rate to ensure the deposition of a good passivation layer on the graphite electrode.

For the ex situ NPD measurements, the cylindrical cells were charged to the desired potential $(4.5$ or $4.75 \mathrm{~V}$ ) at the $\mathrm{C} / 25$ rate and held for $5 \mathrm{~h}$ in the potentiostatic mode (cycling curve shown in Figure S2). Then, the electrodes were extracted and washed in DMC to remove remaining salts. Finally, the electrode masses were gently scratched from the current collectors, and the powder was placed into an air-tight vanadium can, which is nearly transparent to the neutron beam.

The NPD patterns were acquired at the high resolution powder thermal neutron diffractometer HRPT at the Swiss Spallation Neutron Source (SINQ) at Paul Scherrer Institute. ${ }^{16}$ The neutron beam with a wavelength of $1.494 \AA$ A was obtained by a (533) reflection from the vertically focusing Ge-monochromator. The high intensity mode of the instrument was used; each individual scan took about 40 minutes. The background and any coherent scattering from the sample environment pieces or air around the cell on the sample table were effectively eliminated by the use of the 
oscillating radial collimator around the sample position. The diffraction signal was registered by a position-sensitive detector in the angular range between 5 and $165^{\circ} 2 \theta$. The cell was mounted straight over the middle of the sample table, thus horizontally and vertically matching the best beam conditions. The adjustable beam reduction in front of the sample table allowed to efficiently remove the scattering from unwanted pieces in the construction of the cylindrical cell, thus maximising the peak to background ratio for exactly the region where the active materials were situated. The aperture of the beam was rectangular in shape $(20 \mathrm{~mm} \times 18 \mathrm{~mm})$. Rietveld refinements of the diffraction patterns were performed using the FULLPROF package. ${ }^{17}$

\section{RESULTS AND DISCUSSION}

First, the electrochemical performance of the cylindrical cells was tested. The first two cycles were always performed at the $\mathrm{C} / 10$ rate in order to obtain a good passivation layer on the graphite. Typical galvanostatic profiles are represented in Figure 2a. As can be seen, the first cycle differs from the second cycle in the $\sim 3.2-4.4 \mathrm{~V}$ region, due to SEI formation on the graphite electrode. ${ }^{18}$

To properly assess the cells, three different rates were used $(\mathrm{C} / 10, \mathrm{C} / 5$, and $1 \mathrm{C})$; the electrochemical performance results are plotted in Figure $2 \mathrm{~b}$ and compared to a reference cointype cell. Clearly, the lower is the cycling rate, the higher are the initial capacities for the first 10 cycles. Unfortunately, however, stronger fading is also observed at lower C rates. Indeed, more than $95 \%$ of the available capacity is obtained at the $\mathrm{C} / 10$ rate in the first cycles, but it drops to roughly $80 \%$ after 50 cycles. At the $\mathrm{C} / 5$ rate, the starting capacity is $\sim 92 \%$ but decreases to $\sim 82 \%$ after 50 cycles. At the $1 \mathrm{C}$ rate, only $\sim 80 \%$ of the total capacity is obtained for the first cycle, but this only fades by $\sim 5 \%$ after 50 cycles, affording a capacity retention of $75 \%$. For comparison, at the $1 \mathrm{C}$ rate, the standard coin-cell-like design performs better with $\sim 4-6 \%$ more capacity (Figure 
$2 b$, green curve). These small variations are acceptable if we consider the higher loading of the electrodes in the cylindrical cell (ca. $10 \mathrm{mg} / \mathrm{cm}^{2}$ ) compared to the coin-cell type (ca. $7 \mathrm{mg} / \mathrm{cm}^{2}$ ). Indeed, a better current density distribution is expected with the coin-cell design due to its smaller electrodes (13 mm diameter) with a better electrical contact and more uniform mechanical pressure.
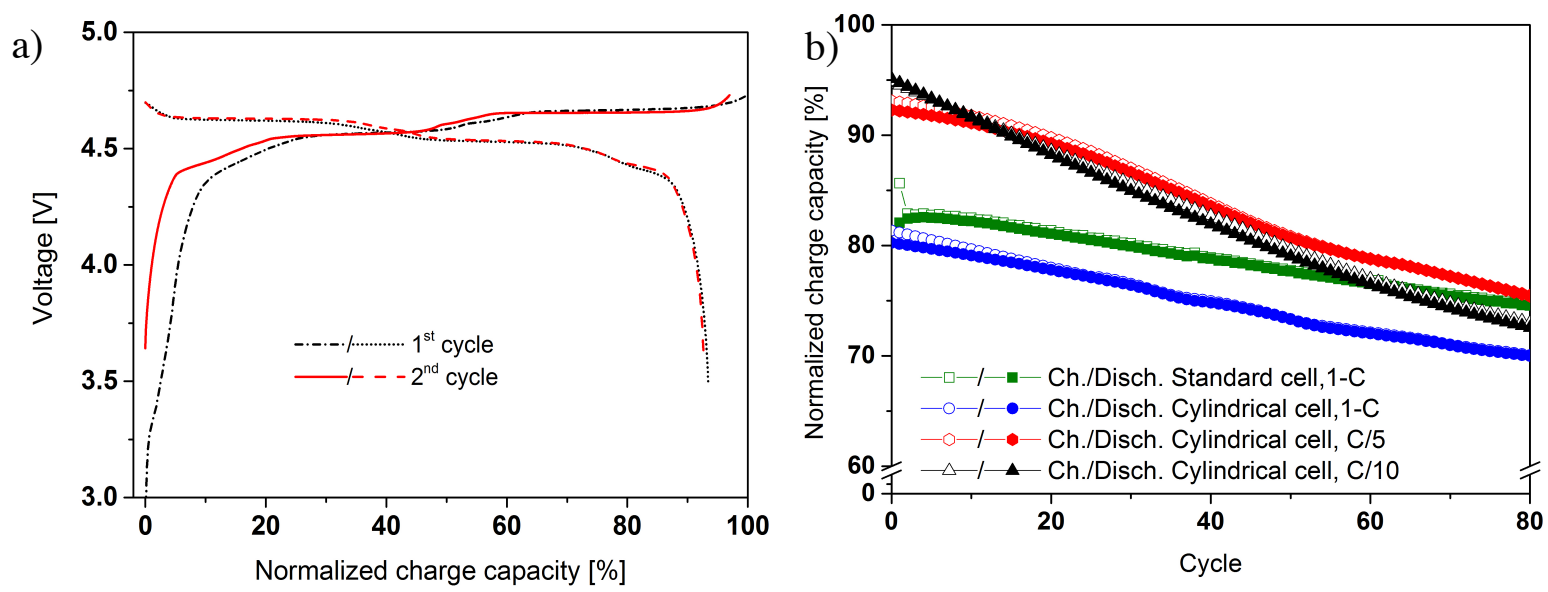

Figure 2. a) Galvanostatic profile obtained from the cycling of the cylindrical cell at the $\mathrm{C} / 10$ rate. b) Evolution of the normalized capacity (to the first charge) with cycling of the cylindrical cell at the $1 \mathrm{C}, \mathrm{C} / 5$, and $\mathrm{C} / 10$ rates, compared to the standard coin-type cell used here as a reference.

As stated before, the first cycle was not performed on the beamline to develop a good passivation layer on the graphite and to ensure the good electrochemical performance of the cell; thus, only the second cycle was measured in the neutron beam. Figure 3 presents the Rietveld refinement of the neutron diffraction pattern obtained in discharge state and then at open-circuit voltage (OCV) for $80 \mathrm{~min}$. As can be seen, six phases are needed to fully refine this pattern. A few contributions are attributed to various parts of the cell (nickel, iron, copper, and aluminum), and the observed background is caused by the incoherent scattering of hydrogen (mainly from the polymer separator) and the liquid electrolyte. The d-LNMO phase was refined using the $F d-3 m$ space group 
with a lattice parameter of 8.160(2) $\AA$, which is slightly lower than the pristine d-LNMO $\left(8.172^{\circ} \AA\right)$ (ICSD $\left.n^{\circ} 180032\right)$ reported elsewhere (Figure S1 and Table S1). ${ }^{1920}$ This difference can be explained by the fact that the cell was pre-cycled and, therefore, part of the lithium was consumed, mainly to form the SEI at the graphite anode. As a consequence, the system no longer possessed enough lithium to fully lithiate the d-LNMO during the following cycles. Simultaneously, the graphite phase was refined using the $P 6_{3} / m m c$ space group with lattice parameters of $a=b=$ $2.460(2)^{\circ} \AA$ and $c=6.712(2)^{\circ} \AA$, which are close to known literature values, e.g. those of Trucano et al. ${ }^{21}$

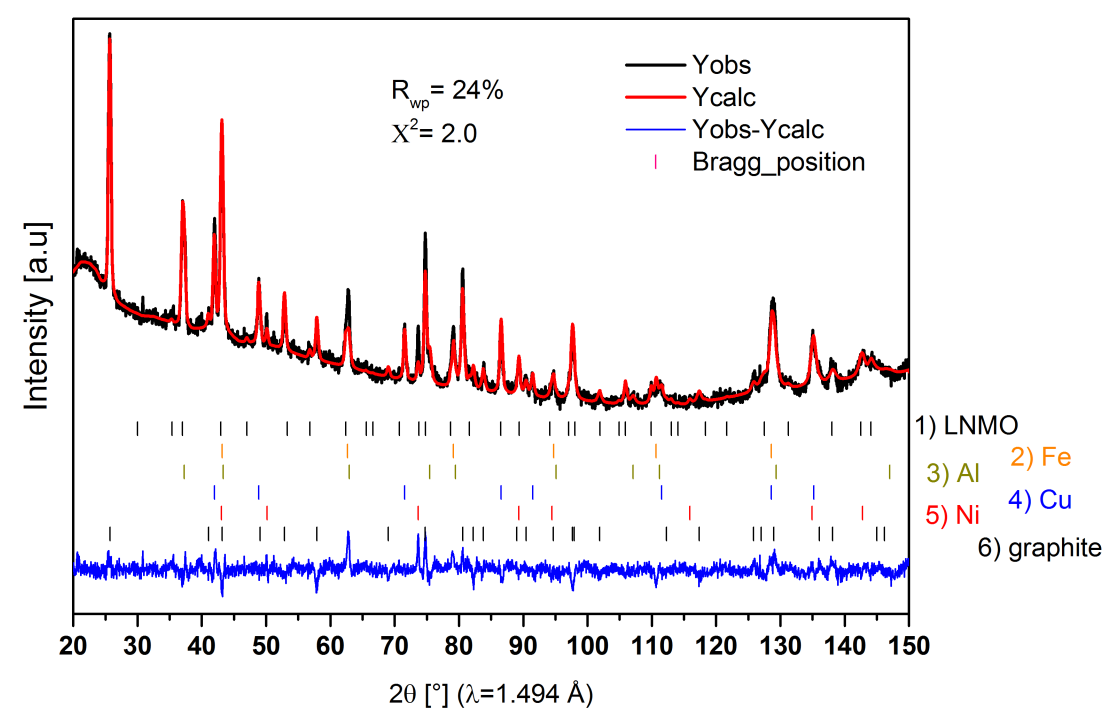

Figure 3. Rietveld refinement of the neutron diffraction pattern recorded at the OCV.

For the operando NPD measurements, the cell was cycled at the $\mathrm{C} / 25$ rate. The main reflections of the two electroactive materials were monitored: the (002) reflection for graphite and the (222) reflection for d-LNMO, respectively. The structural evolution of the (002) reflection of graphite is plotted in Figure 4. The different stages of graphite lithiation (namely, stages 1L, 4L, 3L, 2L, 2, and 1$)^{18,22,23}$ can be clearly ascertained. Indeed, a shift to lower angles of the graphite (002) peak is registered when the cylindrical cell reaches $4.4 \mathrm{~V}(\sim 1 \mathrm{~h})$, and corresponds to the transition of the 
graphite to stage $1 \mathrm{~L}$ (solid-solution of lithium in graphite) with an expansion of ca. $0.8 \%$ along the $c$-axis $\left(a=b=2.461(2)^{\circ} \AA\right.$ and $c=6.764(2)^{\circ} \AA, P 6_{3} / m m c$, in agreement with a previous study $\left.{ }^{24}\right)$. This shift continues further until $4.45 \mathrm{~V}(\sim 3 \mathrm{~h})$, with a decrease and then an increase of the peak intensity, as already reported in the literature..$^{25,26}$ This phase change is attributed to the solidsolution reaction from stage $1 \mathrm{~L}$ to stage $4 \mathrm{~L}\left(\mathrm{LiC}_{24}\right)$ with an expansion of the lattice parameter $c$ from $6.764(2)$ to $6.879(2)^{\circ} \AA$, corresponding to a volume expansion of ca. $1.02 \%$ along the $c$-axis, while the $a$ parameter stays constant $\left(P 6_{3} / m m c\right.$ space group). From $25^{\circ}$ to $24.5^{\circ}$ and between 4.45 and $4.55 \mathrm{~V}$, the shift is ascribed to the stage $4 \mathrm{~L}$-to-stage $2\left(\mathrm{LiC}_{12}\right)$ transition, with new lattice parameters of $a=b=4.288(2)^{\circ} \AA$ and $c=7.042(2)^{\circ}\left(P 6 / \mathrm{mmm}\right.$ space group, ICSD $\left.\mathrm{n}^{\circ} 193440\right)$. This finding is similar to the work of Billaud et al.,22 and results in an expansion of ca. $2.3 \%$ along the $c$-axis. Finally, stage $1\left(\mathrm{LiC}_{6}\right)$ manifests itself by appearance of a clear peak at $\sim 23.23^{\circ}$ when the voltage of the cylindrical cell is above $4.6 \mathrm{~V}$; the lattice parameters of the fully lithiated graphite are $a=b=4.299(2) \AA$ and $c=3.702(2) \AA\left(P 6 / \mathrm{mmm}\right.$ space group, ICSD $\left.{ }^{\circ}{ }^{\circ} 191311\right)$, in agreement with the literature. ${ }^{22,24,27}$ This last transition is responsible for the larger expansion $(\sim 5.1 \%$ along the $c$-axis) and it is known to be kinetically limited ${ }^{23}$ however, no lithium plating is detected. In total, the $c$-axis expands by $\sim 9.2 \%$. The presence of stage 2 until the end of the charge is explained by the balancing used between the (oversized) negative and positive electrodes. During discharge, the processes are reversed and the unit cell parameters return to their starting values. 


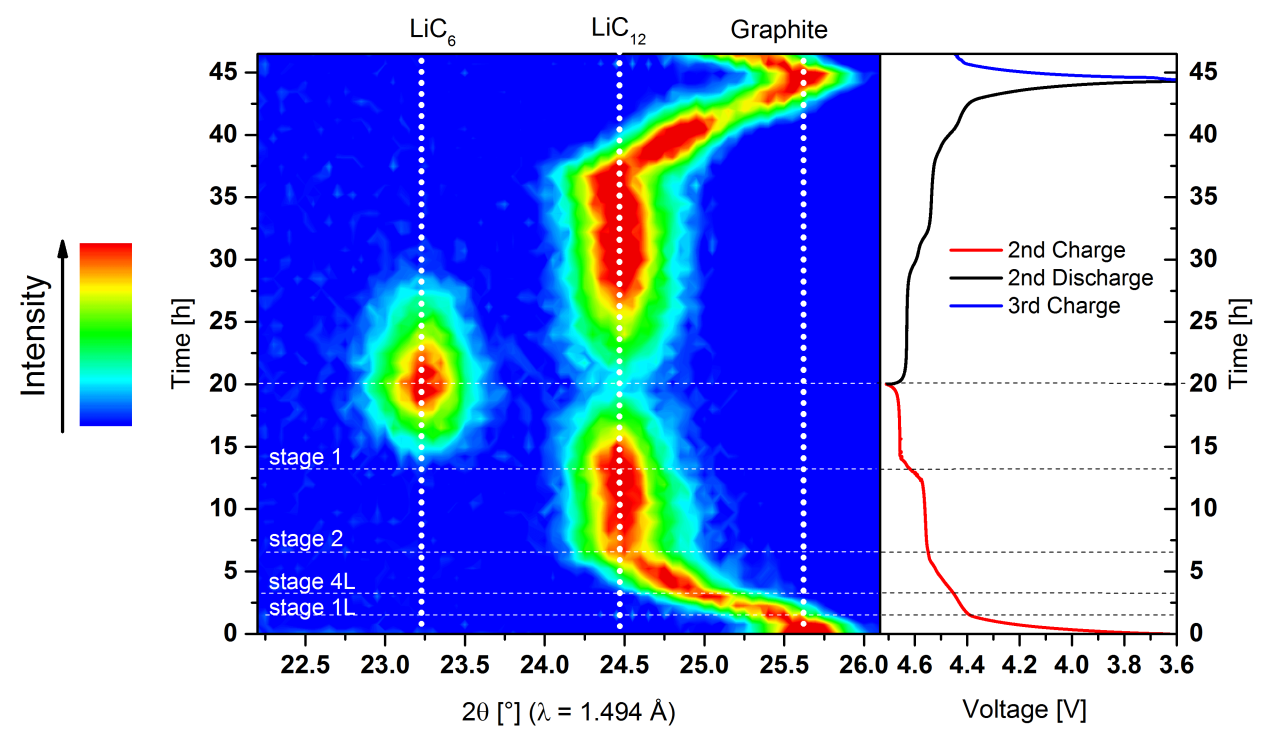

Figure 4. Contour plot representation obtained from operando NPD patterns: The (002) graphite reflection is plotted at left and the galvanostatic cycle of the operando cell at right.

Simultaneously, we followed the structural evolution of d-LNMO (Figure 5). We observed a shift of the peak (222) to higher angles in two steps: i) a solid-solution reaction (involving the $\mathrm{Ni}^{2+} / \mathrm{Ni}^{3+}$ redox couple) corresponding to the half delithiation of d-LNMO, followed by ii) a twophase reaction (involving the $\mathrm{Ni}^{3+} / \mathrm{Ni}^{4+}$ redox couple), leading to the formation of fully delithiated d-LNMO. ${ }^{28}$ To refine these different intermediate phases, the fully lithiated d-LNMO (ICSD $\mathrm{n}^{\circ} 180032$ ) model was used, and the lattice parameters and lithium content were adjusted accordingly. For the first step, this shift leads to a reduction in the lattice parameters from 8.160(2) to $8.089(2)^{\circ} \AA(\sim 2.6 \%$ volume shrinkage $)$, and from $8.093(2)$ to $8.002(2)^{\circ} \AA$ for the second, leading to a total volume reduction of $\sim 6.1 \%$. These values are in agreement with previously reported work. ${ }^{29,30}$ At the end of the charge, the half and fully delithiated phases are visible in a ratio of $\sim 27(1) \%$ and $\sim 73(1) \%$, respectively. Unfortunately, a portion of the d-LNMO could not be fully delithiated, leading us to conclude that the electrode did not react homogeneously. During discharge, these processes are reversed; however, the d-LNMO returns to a lattice parameter of 
$8.160(3)^{\circ} \AA$, which is slightly different from the pristine material at $8.172^{\circ} \AA$. This demonstrates that the amount of lithium available is slightly less than stoichiometric (less than 1), since a small amount is immobilized in the SEI formation process.

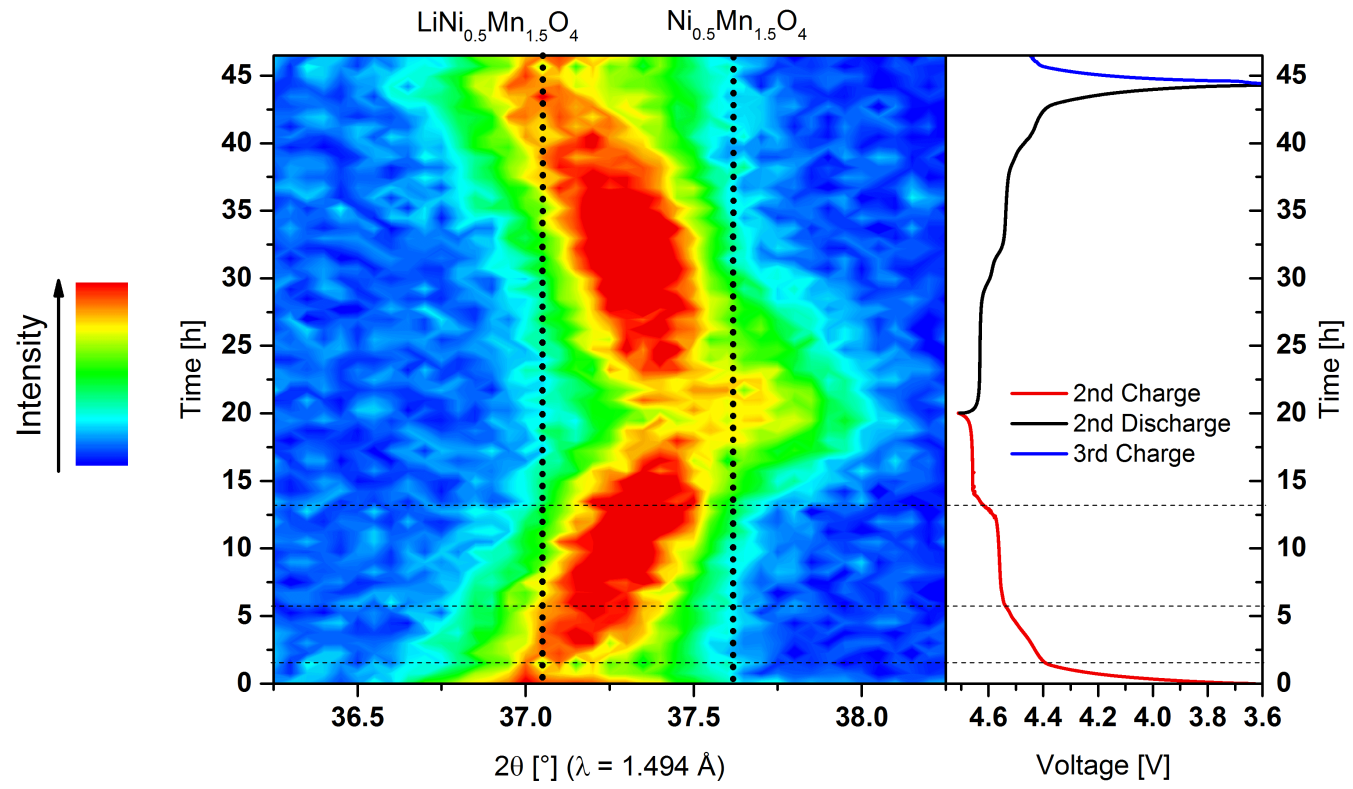

Figure 5. Contour plot representation obtained from operando NPD patterns: The (222)

LNMO reflection is plotted at left and the galvanostatic cycle of the operando cell at right.

In order to quantify the loss of lithium during the first charge, ex situ samples extracted from other cylindrical cells were measured (Rietveld refinements, patterns, and values from the ex situ samples can be found in Figures S1 and S3, and Tables S1-4).

Figure 6a shows the Rietveld refinement of the fully charged d-LNMO electrode. Two cubic phases $(F d-3 m)$ were used for this refinement: i) a main phase with a lattice parameter of 8.010(1) $\AA$, which represents $\sim 94 \%$ of the sample, and ii) a second phase with a lattice parameter of 8.094(1) $\AA$, corresponding roughly to $6 \%$ of the sample. The main phase was refined using the atomic positions as in d-LNMO but with the lithium content equal to zero, indicating a fully 
delithiated phase. The second phase was also refined using the same structure as d-LNMO, but the lithium content was found to be equivalent to a half-charged electrode (Figure S3 and Table S2). This indicates that the reaction was not fully completed and a small portion of the d-LNMO particles could not properly react, even with a slow cycling rate and a potentiostatic step. Contrary to the report by Pang et al., ${ }^{30}$ no changes in the oxygen positions are observed. The background bump observed between $20^{\circ}$ and $27^{\circ}$ is due to the presence of the PVDF binder, which contains hydrogen. It is important to note that, for all the d-LNMO samples, a NiO impurity was found (less than $1 \%$ ) and refined in the $F m-3 m$ space group with a unit cell parameter of $4.145(1) \AA$.

Figure $6 \mathrm{~b}$ shows the Rietveld refinement of the fully charged graphite electrode. Two hexagonal phases (both $P 6 / \mathrm{mmm}$ ) were needed to refine this pattern. The main phase was refined using $a=b=4.317(1) \AA$ and $c=3.703(1) \AA$ as cell parameters (ICSD n ${ }^{\circ} 191311$ ), which corresponds to stage $1 \mathrm{LiC}_{6}$, as described in the literature..$^{22,31-33}$ The best fit was obtained with a slight deficiency of lithium $\left(\mathrm{Li}_{\sim 0.9} \mathrm{C}_{6}\right)$, which is explained by the incomplete lithiation of the graphite. The proportion of this phase was found to be $\sim 80 \%$. The second phase was refined with cell parameters of $a=b=4.295(1) \AA$ and $c=7.050(1) \AA$ (attributed to stage 2 of the graphite-lithium intercalation, ICSD $\left.n^{\circ} 193440\right){ }^{33}$ Its stoichiometry was found to be ca. $\mathrm{Li}_{\sim 0.75} \mathrm{C}_{12}$ (due to the lithiation of a portion of stage 2 into stage 1), and it constituted $20 \%$ of the sample composition. The presence of this phase can be explained by the balancing between the positive and (oversized) negative electrodes. Since graphite is used in excess to prevent lithium plating and dendrite formation, there is insufficient lithium in the d-LNMO to passivate and fully lithiate the graphite, generating the inhomogeneity. ${ }^{18}$ 
a)

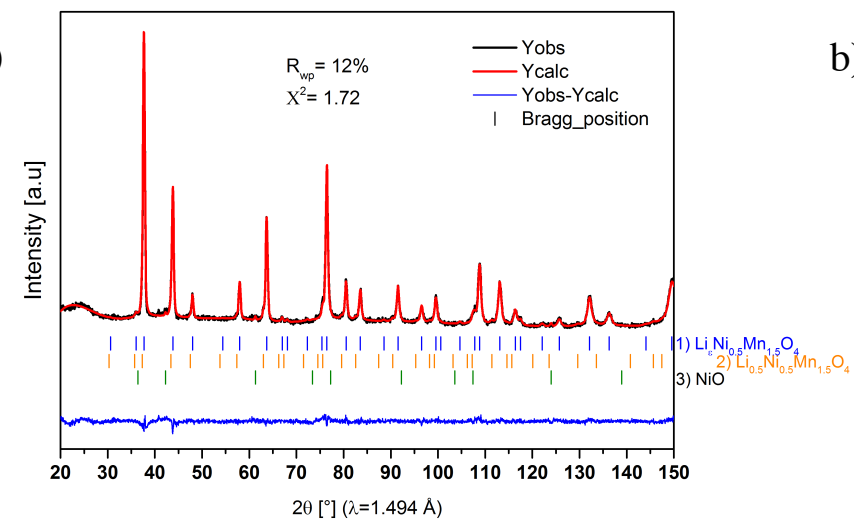

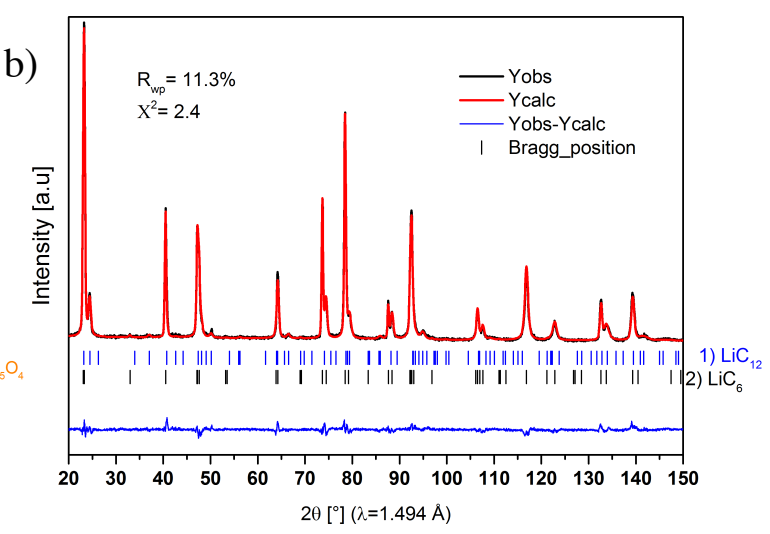

Figure 6. Rietveld refinement of ex situ NPD of fully charged electrodes: a) d-LNMO and b) graphite.

Through the Rietveld refinement, we could estimate the amount of lithium which reacted during cycling. After the first charge, we found that $\sim 96.6( \pm 2) \%$ of the lithium was extracted from the dLNMO electrode and was transferred to or reacted with the graphite electrode but $\sim 6.8( \pm 2) \%$ of the transferred lithium could not be located within the lithiated graphite. This "loss" of lithium is well correlated to the capacity loss observed during the first electrochemical process in the voltage range of 3.2-3.9 V, attributed to SEI formation (estimated at ca. 7\%, based on our specific charge calculations).

\section{CONCLUSION}

A novel cylindrical cell has been developed that combines reliable electrochemical performance and the option to use a deuterated electrolyte. Nearly two grams of d-LNMO were cycled and probed via operando NPD measurements. The cell shows good cycling performance, especially at the $1 \mathrm{C}$ rate, which is generally challenging because of the high loading of the active materials. Using operando neutron powder diffraction, the two electroactive materials, d-LNMO and graphite, could be monitored during charge and discharge with respect to volume shrinkage 
or expansion. These volume changes were then correlated with the lithium content of each phase through the Rietveld refinement analysis of ex situ measurements. The lithium loss due to SEI formation was in agreement with the smaller lattice parameter of the d-LNMO after the first charge, indicating that insufficient amount of lithium was available to relithiate the d-LNMO (7\% Li was consumed). This approach provides important insights by which to further optimize the loading balance of the electroactive materials, especially for high voltage systems in which side reactions play important roles and lithium consumption can occur during cycling.

\section{ASSOCIATED CONTENT}

\section{AUTHOR INFORMATION}

\section{Corresponding Author}

*E-mail: claire.villevieille@psi.ch Tel: +41 563102410

\section{Notes}

The authors declare no competing financial interest. 


\section{ACKNOWLEDGMENT}

The authors are grateful to SAFT for financial support. This work is based on experiments performed at the Swiss spallation neutron source SINQ at the Paul Scherrer Institute, Villigen, Switzerland.

Supporting Information. Galvanostatic curves from the cylindrical cells used for the ex situ sample; complete set of results from the Rietveld refinements of the ex situ measurements for the d-LNMO pristine powder, half and fully charged d-LNMO electrodes, and fully charged graphite electrode. This material is available free of charge via the Internet at http://pubs.acs.org.

\section{REFERENCES}

(1) Liu, D.; Zhu, W.; Trottier, J.; Gagnon, C.; Barray, F.; Guerfi, A.; Mauger, A.; Groult, H.; Julien, C. M.; Goodenough, J. B.; et al. Spinel Materials for High-Voltage Cathodes in LiIon Batteries. RSC Adv. 2014, 4, 154-167.

(2) Terada, Y.; Yasaka, K.; Nishikawa, F.; Konishi, T.; Yoshio, M.; Nakai, I. In Situ XAFS Analysis of $\mathrm{Li}(\mathrm{Mn}, \mathrm{M}) 2 \mathrm{O} 4(\mathrm{M}=\mathrm{Cr}$, Co, Ni) 5V Cathode Materials for Lithium-Ion Secondary Batteries. J. Solid State Chem. 2001, 156, 286-291.

(3) Kunduraci, M.; Amatucci, G. G. Synthesis and Characterization of Nanostructured 4.7 V Li[sub x] Mn[sub 1.5]Ni[sub 0.5]O[sub 4] Spinels for High-Power Lithium-Ion Batteries. J. Electrochem. Soc. 2006, 153, A1345-A1352.

(4) Hu, M.; Pang, X.; Zhou, Z. Recent Progress in High-Voltage Lithium Ion Batteries. J. Power Sources 2013, 237, 229-242. 
(5) Manthiram, A.; Chemelewski, K.; Lee, E.-S. A Perspective on the High-Voltage LiMn1.5Ni0.5O4 Spinel Cathode for Lithium-Ion Batteries. Energy Environ. Sci. 2014, 7, $1339-1350$.

(6) Xu, M.; Zhou, L.; Dong, Y.; Chen, Y.; Garsuch, a.; Lucht, B. L. Improving the Performance of Graphite/ LiNi0.5Mn1.5O4 Cells at High Voltage and Elevated Temperature with Added Lithium Bis(oxalato) Borate (LiBOB). J. Electrochem. Soc. 2013, 160, A2005-A2013.

(7) Kim, J.-H.; Pieczonka, N. P. W.; Li, Z.; Wu, Y.; Harris, S.; Powell, B. R. Understanding the Capacity Fading Mechanism in LiNi0.5Mn1.5O4/graphite Li-Ion Batteries. Electrochim. Acta 2013, 90, 556-562.

(8) Jarry, A.; Gottis, S.; Yu, Y.-S.; Roque-Rosell, J.; Kim, C.; Cabana, J.; Kerr, J.; Kostecki, R. The Formation Mechanism of Fluorescent Metal Complexes at the LiXNi0.5Mn1.5O4- $\delta$ /Carbonate Ester Electrolyte Interface. J. Am. Chem. Soc. 2015, 137, 3533-3539.

(9) He, M.; Boulet-Roblin, L.; Borel, P.; Tessier, C.; Novák, P.; Villevieille, C.; Berg, E. J. Effects of Solvent, Lithium Salt, and Temperature on Stability of Carbonate-Based Electrolytes for 5.0V LiNi0.5Mn1.5O4 Electrodes. J. Electrochem. Soc. 2016, 163, A83A89.

(10) Pieczonka, N. P. W.; Liu, Z.; Lu, P.; Olson, K. L.; Moote, J.; Powell, B. R.; Kim, J. Understanding Transition-Metal Dissolution Behavior in LiNi0.5Mn1.5O4 High-Voltage Spinel for Lithium Ion Batteries. J. Phys. Chem. C 2013, 117, 15947-15957.

(11) Hu, L.; Amine, K.; Zhang, Z. Fluorinated Electrolytes for 5-V Li-Ion Chemistry: Dramatic Enhancement of LiNi0.5Mn1.5O4/graphite Cell Performance by a Lithium Reservoir. Electrochem. commun. 2014, 44, 34-37. 
(12) Roberts, M.; Biendicho, J. J.; Hull, S.; Beran, P.; Gustafsson, T.; Svensson, G.; Edström, K. Design of a New Lithium Ion Battery Test Cell for in-Situ Neutron Diffraction Measurements. J. Power Sources 2013, 226, 249-255.

(13) Pang, W. K.; Peterson, V. K. A Custom Battery for Operando Neutron Powder Diffraction Studies of Electrode Structure. J. Appl. Crystallogr. 2015, 48, 280-290.

(14) Sharma, N.; Peterson, V. K.; Elcombe, M. M.; Avdeev, M.; Studer, A. J.; Blagojevic, N.; Yusoff, R.; Kamarulzaman, N. Structural Changes in a Commercial Lithium-Ion Battery during Electrochemical Cycling: An in Situ Neutron Diffraction Study. J. Power Sources 2010, 195, 8258-8266.

(15) Boulet-Roblin, L.; Kazzi, M. El; Novák, P.; Villevieille, C. Surface/Interface Study on Full xLi2MnO3·(1 - x)LiMO2 $(\mathrm{M}=\mathrm{Ni}, \mathrm{Mn}, \mathrm{Co}) /$ Graphite Cells. J. Electrochem. Soc. 2015, 162, A1297-A1300.

(16) Fischer, P.; Frey, G.; Koch, M.; Konnecke, M.; Pomjakushin, V.; Schefer, J.; Thut, R.; Schlumpf, N.; Burge, R.; Greuter, U.; et al. High-Resolution Powder Diffractometer HRPT for Thermal Neutrons at SINQ. Phys. B Condens. Matter 2000, 276-278, 146-147.

(17) Rodríguez-Carvajal, J. Recent Advances in Magnetic Structure Determination by Neutron Powder Diffraction. Phys. B Condens. Matter 1993, 192, 55-69.

(18) Verma, P.; Maire, P.; Novák, P. A Review of the Features and Analyses of the Solid Electrolyte Interphase in Li-Ion Batteries. Electrochim. Acta 2010, 55, 6332-6341.

(19) Kunduraci, M.; Amatucci, G. G. The Effect of Particle Size and Morphology on the Rate Capability of $4.7 \mathrm{~V}$ LiMn1.5+ $\delta \mathrm{Ni0} .5-\delta \mathrm{O} 4$ Spinel Lithium-Ion Battery Cathodes. Electrochim. Acta 2008, 53, 4193-4199. 
(20) Boulet-Roblin, L.; Villevieille, C.; Borel, P.; Tessier, C.; Novák, P.; Ben Yahia, M. Versatile Approach Combining Theoretical and Experimental Aspects of Raman Spectroscopy to Investigate Battery Materials: The Case of LiNi0.5Mn1.5O4 Spinel. J. Phys. Chem. C 2016, acs.jpcc.6b04155.

(21) Trucano, P.; Chen, R. Structure of Graphite by Neutron Diffraction. Nature 1975, 258, 136137.

(22) Billaud, D.; Henry, F. X.; Lelaurain, M.; Willmann, P. Revisited Structures of Dense and Dilute Stage II Lithium-Graphite Intercalation Compounds. J. Phys. Chem. Solids 1996, 57, $775-781$.

(23) Hess, M.; Novák, P. Shrinking Annuli Mechanism and Stage-Dependent Rate Capability of Thin-Layer Graphite Electrodes for Lithium-Ion Batteries. Electrochim. Acta 2013, 106, $149-158$.

(24) Hess, M. Kinetics and Stage Transitions of Graphite for Lithium-Ion Batteries. ETH / PSI 2013.

(25) Sharma, N.; Peterson, V. K. Overcharging a Lithium-Ion Battery: Effect on the LixC6 Negative Electrode Determined by in Situ Neutron Diffraction. J. Power Sources 2013, 244, 695-701.

(26) Cai, L.; An, K.; Feng, Z.; Liang, C.; Harris, S. J. In-Situ Observation of Inhomogeneous Degradation in Large Format Li-Ion Cells by Neutron Diffraction. J. Power Sources 2013, 236, 163-168.

(27) Dahn, J. R.; Fong, R.; Spoon, M. J. Suppression of Staging in Lithium-Intercalated Carbon by Disorder in the Host. Phys. Rev. B 1990, 42, 6424-6432. 
(28) Ariyoshi, K.; Iwakoshi, Y.; Nakayama, N.; Ohzuku, T. Topotactic Two-Phase Reactions of $\mathrm{Li}[\mathrm{Ni}[\mathrm{sub}$ 1/2] Mn[sub 3/2]] O[sub 4] (P4[sub 3]32) in Nonaqueous Lithium Cells. $J$. Electrochem. Soc. 2004, 151, A296-A303.

(29) Bianchini, M.; Fauth, F.; Suard, E.; Leriche, J.-B.; Masquelier, C.; Croguennec, L. Spinel Materials for Li-Ion Batteries: New Insights Obtained by Operando Neutron and Synchrotron X-Ray Diffraction. Acta Crystallogr. Sect. B Struct. Sci. Cryst. Eng. Mater. 2015, $71,1-14$.

(30) Pang, W. K.; Sharma, N.; Peterson, V. K.; Shiu, J.-J.; Wu, S. In-Situ Neutron Diffraction Study of the Simultaneous Structural Evolution of a LiNi0.5Mn1.5O4 Cathode and a Li4Ti5O12 Anode in a LiNi0.5Mn1.5O4IILi4Ti5O12 Full Cell. J. Power Sources 2014, $246,464-472$.

(31) Guerard, D.; Herold, a. Intercalation of Lithium into Graphite and Other Carbons. Carbon N. Y. 1975, 13, 337-345.

(32) Dahn, J. R. Phase Diagram of LixC6. Phys. Rev. B 1991, 44, 9170-9177.

(33) Dolotko, O.; Senyshyn, a.; Muhlbauer, M. J.; Nikolowski, K.; Scheiba, F.; Ehrenberg, H. Fatigue Process in Li-Ion Cells: An In Situ Combined Neutron Diffraction and Electrochemical Study. J. Electrochem. Soc. 2012, 159, A2082-A2088. 
FOR TABLE OF CONTENTS USE ONLY

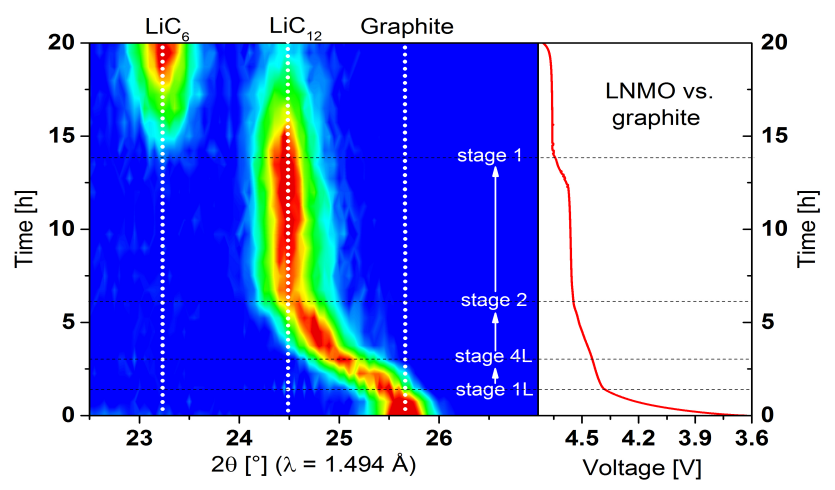

